\title{
Analgesic Effect of Preoperative Pentazocine for Laparoscopic Cholecystectomy
}

\author{
Na Wang ${ }^{1}$, Lei Wang ${ }^{2}$, Yang Gao ${ }^{1}$, Honglan Zhou ${ }^{3}$, Jinguo Wang ${ }^{4}$ \\ 1. Department of Anesthesiology, The First Hospital of Jilin University 2. Department of Cardiovascular \\ Surgery, The First Hospital of Jilin University 3. Department of Urology, The First Hospital of Jilin \\ University 4. Department of Urology, The First Hospital of Jilin University
}

$\square$ Corresponding author: Jinguo Wang, wangjinguolily@163.com

Disclosures can be found in Additional Information at the end of the article

\section{Abstract}

Objective: To assess whether preoperative pentazocine can reduce intraoperative hemodynamic changes and postoperative pain.

Methods: Fifty patients undergoing laparoscopic cholecystectomy were randomized into two groups. Group P received intravenous $0.5 \mathrm{mg} / \mathrm{kg}$ pentazocine $10 \mathrm{~min}$ before surgery, and Group $\mathrm{C}$ received normal saline as a placebo. A standardized general anesthesia was conducted in all patients. Mean blood pressure (MBP), heart rate (HR), and visual analog scale (VAS) scores at various time points were recorded. The tramadol consumption during the study period was recorded.

Results: Group P had lower VAS scores at two, four, and eight hours postoperatively compared with Group C. MBP and HR rose significantly because of pneumoperitoneum within Group C, and no significant changes were detected in MBP and HR within Group P. Tramadol doses given were statistically fewer in Group P.

Conclusion: Preoperative intravenous pentazocine can decrease intraoperative hemodynamic changes and postoperative pain.

Received 07/05/2016

Review began 07/07/2016

Review ended 12/19/2016

Published 12/31/2016

(c) Copyright 2016

Wang et al. This is an open access article distributed under the terms of the Creative Commons Attribution License CC-BY 3.0., which permits unrestricted use, distribution, and reproduction in any medium, provided the original author and source are credited.
Categories: Anesthesiology, Pain Management

Keywords: pentazocine, preemptive analgesia, laparoscopy, stress reaction, postoperative pain

\section{Introduction}

Although laparoscopic surgery is associated with less tissue damage than open surgery, intraoperative stress reaction and postoperative pain are still common. Preemptive analgesia is a pretreatment which prevents the establishment of central sensitization that can amplify the upcoming pain. Various drugs have been used for this analgesic method. Pentazocine, which acts as an agonist of Kappa receptors ( $\mathrm{K}$ receptors) and partial agonist/antagonist of $\mathrm{M}$ receptors, has been widely used to treat moderate to severe pain. It is recognized that pentazocine has an adequate analgesic efficacy with relatively weak respiratory depression and addiction [1-2].

We designed this clinical research to assess the analgesic efficacy of preoperative intravenous pentazocine for laparoscopic cholecystectomy under general anesthesia. 


\section{Materials And Methods}

After approval of the Institutional Ethics Committee of the First Hospital of Jilin University (approval \#2016-291) and obtaining written informed consent from the participants, this randomized and double-blinded study was conducted on 50 patients undergoing laparoscopic cholecystectomy under a standardized general anesthesia. Patients allergic to the study drugs, with American Society of Anesthesiologists (ASA) physical status more than two, a history of drug abuse, communication difficulties, and morbidly obese (body mass index $>30 \mathrm{~kg} / \mathrm{m}^{2}$ ) patients were excluded from this study.

Randomization was performed with a computer-generated sequence of numbers and sealed envelopes. Group P received $0.5 \mathrm{mg} / \mathrm{kg}$ pentazocine (pentazocine, CR Double-

Crane Pharmaceuticals Co. Ltd, Beijing, China) 10 min before the surgery, and Group C received a placebo of normal saline. The study medications were prepared by a researcher who was not involved in the management of anesthesia. The other researchers and patients were blind to the grouping allocation. All patients were instructed on the visual analog scale (VAS) preoperatively and its use as a method for measuring postoperative pain.

After shifting the patients to the operating theatre, electrocardiogram (ECG), heart rate (HR), blood pressure (BP), Narcotrend index (NI), end-tidal carbon dioxide, and oxygen saturation $\left(\mathrm{SpO}_{2}\right)$ were monitored. Normal saline was infused at the rate of $8 \sim 10 \mathrm{ml} / \mathrm{kg} / \mathrm{h}$. Anesthetic induction was conducted using $0.03 \mathrm{mg} / \mathrm{kg}$ midazolam, $0.3 \mathrm{mg} / \mathrm{kg}$ etomidate, $4 \mu \mathrm{g} / \mathrm{kg}$ fentanyl, and $0.15 \mathrm{mg} / \mathrm{kg}$ cisatracurium. Anesthesia was maintained with 6 to $8 \mathrm{mg} / \mathrm{kg} / \mathrm{h}$ propofol, $0.008 \mathrm{mg} / \mathrm{kg} / \mathrm{h}$ remifentanil, and intermittent administration of cisatracurium as needed. Intravenous $1 \mathrm{\mu g} / \mathrm{kg}$ fentanyl was given to all patients about $10 \mathrm{~min}$ before the completion of the surgery.

Mean blood pressure (MBP) and HR were measured and recorded every five minutes. The pain intensity was assessed by a linear $10 \mathrm{~cm}$ visual analog scale (VAS: 0- no pain; 1, 2, 3 - mild pain; 4, 5, 6 - moderate pain; 7, 8, 9 - severe pain; 10 - worst imaginable pain); the sedation status was evaluated with the Ramsay sedation scale (RSS: 1 - anxious and agitated, 2 - cooperative and tranquil, 3 - drowsy but responds to command, 4 - asleep but responds to tactile stimulation, and 5 - asleep and no response). VAS scores at rest were evaluated and recorded at two, four, eight, 12, and $24 \mathrm{hrs}$ after extubation of the patients. Postoperative analgesia consisted of $1.5 \mathrm{mg} / \mathrm{kg}$ tramadol, which was administrated intravenously when the patient complained of pain and the VAS score was more than 3 . The time to the first analgesic request and tramadol doses given were recorded.

Adverse effects associated with pentazocine, such as nausea, vomiting, itching, oversedation, and respiratory depression were assessed with a "yes" or "no" survey. Oversedation was defined as respiratory severity score (RSS) equal to five. Respiratory depression was defined as respiratory rate less than 10 breaths $/ \mathrm{min}$ or $\mathrm{SpO}_{2}$ less than 90 .

The time to the first analgesic request was the primary endpoint of this study. According to our clinical experiences, we assumed that preoperative intravenous pentazocine would extend 30 min of this time period; 23 subjects were necessary for each group with two-sided $\alpha$ of $5 \%$ and $\beta$ of $10 \%$. Twenty-five patients were enrolled in each group for possible dropouts.

SPSS 17.0 (SPSS Inc, Chicago, IL, USA) was used for statistical analyses. Data were analyzed with unpaired t-test for normally distributed data, Mann-Whitney U-test for nonnormally distributed data (the number of tramadol doses and VAS scores), and Chi-square or Fisher's exact test for qualitative data. A $p<0.05$ was regarded as statistically significant. 


\section{Cureus}

\section{Results}

No significant difference was found between the two groups in demographic data and surgical characteristics (Table 1).

\begin{tabular}{|c|c|c|c|c|c|}
\hline & Age (yr) & Weight (kg) & Male/Female & ASA I/II & Duration of surgery (min) \\
\hline Group P $(n=25)$ & $45.2 \pm 7.8$ & $56.4 \pm 7.2$ & $11 / 14$ & $19 / 6$ & $26.7 \pm 12.6$ \\
\hline Group C (n = 25) & $47.7 \pm 8.4$ & $54.8 \pm 9.4$ & 10/15 & $21 / 4$ & $28.5 \pm 11.4$ \\
\hline P-value & 0.281 & 0.502 & 1.000 & 0.725 & 0.598 \\
\hline
\end{tabular}

\section{TABLE 1: Demographic Data and Surgical Characteristics}

Values are presented as mean \pm standard deviation and number of patients.

Figures 1 and 2 presented MBP and HR at 5 min after arrival at the operating room (T1), 5 min before surgery (T2), $5 \mathrm{~min}$ (T3), $10 \mathrm{~min}$ (T4), and $15 \mathrm{~min}$ (T5) after pneumoperitoneum. In Group C, MBP at T3 and T4 was significantly higher than MBP at T1 and T2; HR at T3 was higher compared with T1 and HR at T4 was higher compared with T1 and T2 within Group C because of pneumoperitoneum. Significant differences were detected in MBP and HR at T3 and T4 between the two groups, and MBP and HR were higher in Group C (Figures 1-2).

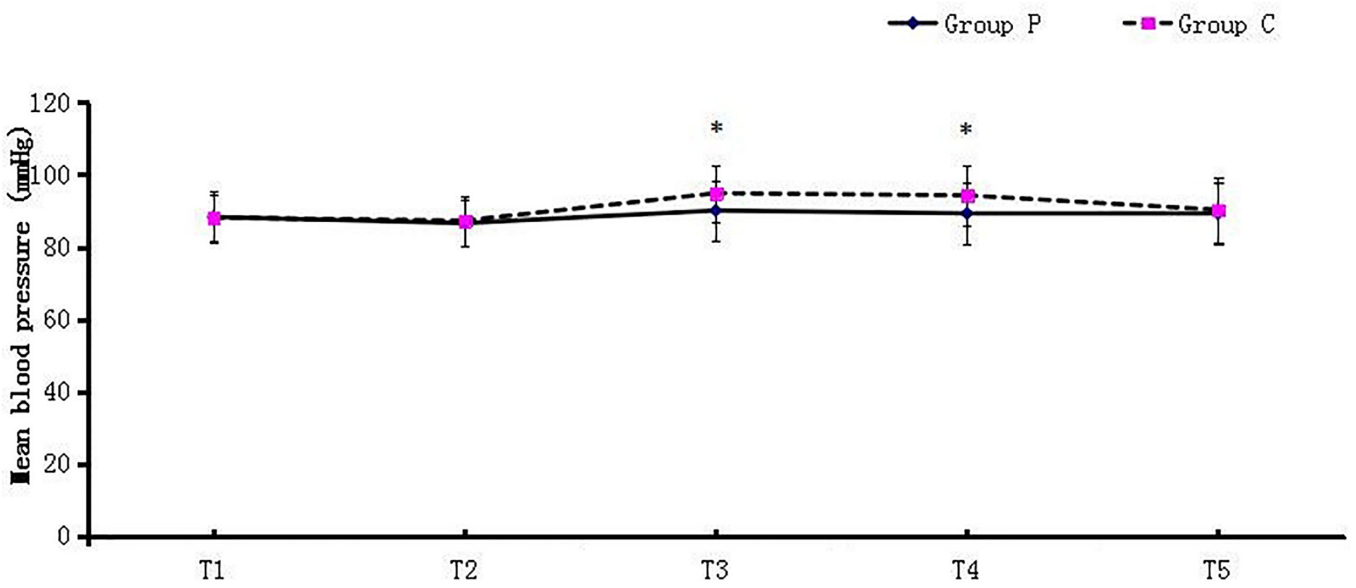

\section{FIGURE 1: Mean Blood Pressure at Various Time Points}

Abbreviations: T1, the time of arrival at the operating room; T2, 5 min before skin incision; T3, T4, and T5, $5 \mathrm{~min}, 10 \mathrm{~min}$, and $15 \mathrm{~min}$ after pneumoperitoneum, respectively. * indicates $\mathrm{p}<$ 0.05 between the two groups. 


\section{Cureus}

Group P --.e⿱日一ㄹ- Group C

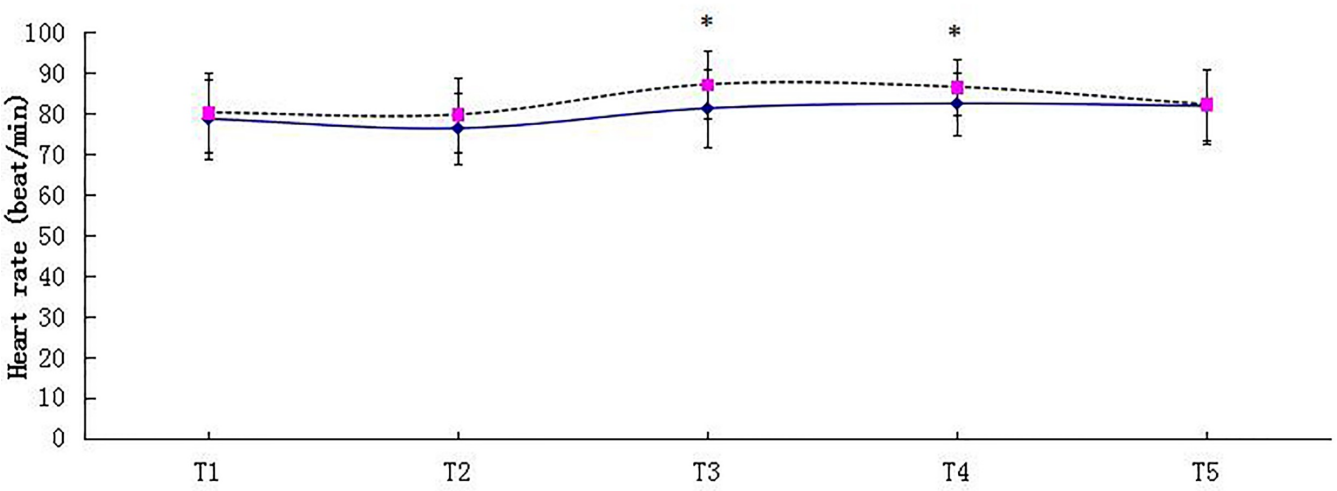

\section{FIGURE 2: Heart Rate at Various Time Points}

Abbreviations: T1, the time of arrival at the operating room; T2, 5 min before skin incision; T3, $\mathrm{T} 4$, and T5, $5 \mathrm{~min}, 10 \mathrm{~min}$, and $15 \mathrm{~min}$ after pneumoperitoneum, respectively. * indicates $\mathrm{p}<$ 0.05 between the two groups.

VAS pain scores at two, four, and eight hrs after surgery were significantly lower in Group P (Figure 3).

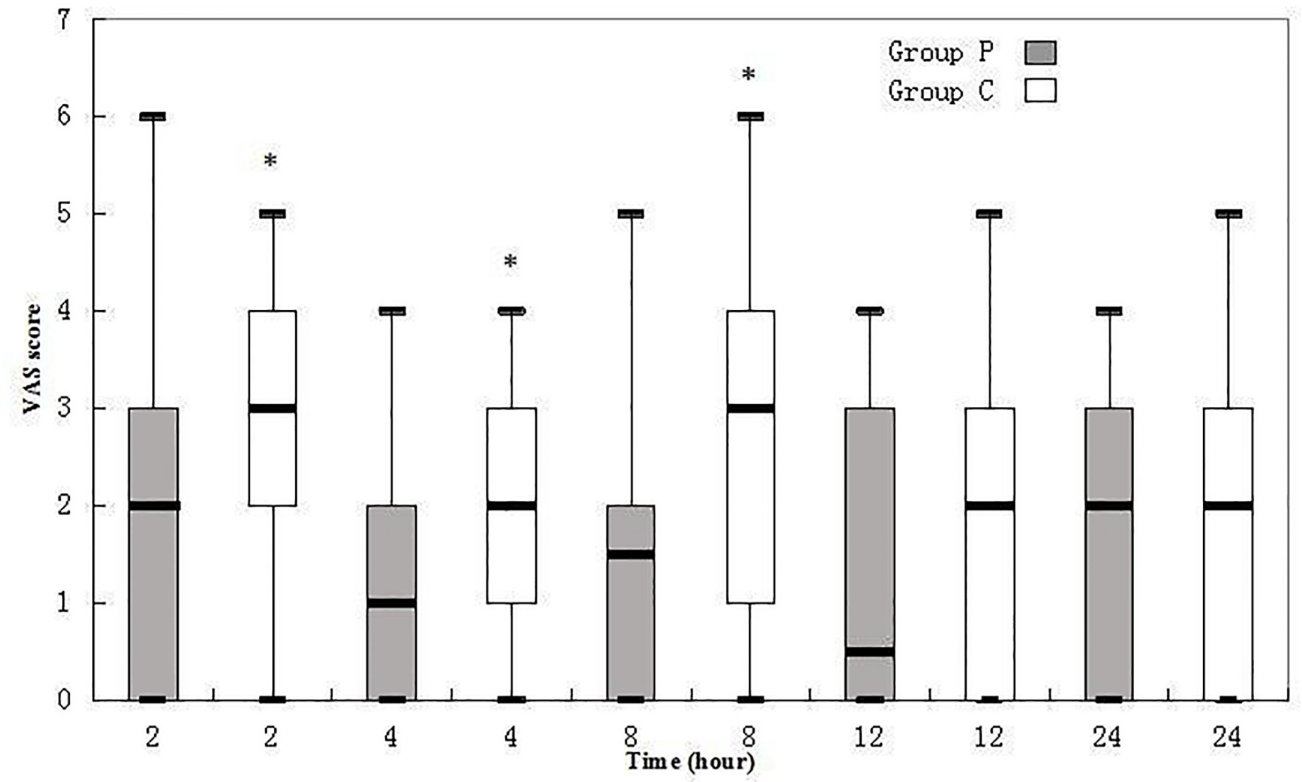

FIGURE 3: Box Plots of VAS Scores at Various Time Points

Results are expressed in the median. The top and bottom of each box indicate 75th and 25th percentiles and the error bars maximum and minimum values.

VAS: visual analogue scale.

* indicates $p<0.05$ compared with the counterpart of Group P. 


\section{Cureus}

The incidence of side effects was comparable between the two groups during the study period. Tramadol doses given were statistically lower in Group P than in Group C $(\mathrm{P}=0.033)$ (Table 2).

\begin{tabular}{|c|c|c|c|c|c|}
\hline & Nausea & Vomiting & Itching & Oversedation & Tramadol consumption (dose) \\
\hline Group P (n = 25) & $4(16 \%)$ & $1(4 \%)$ & $3(12 \%)$ & $1(4 \%)$ & $0.84 \pm 0.85$ \\
\hline Group C (n = 25) & $3(12 \%)$ & $1(4 \%)$ & $2(8 \%)$ & $0(0 \%)$ & $1.36 \pm 0.81$ \\
\hline P-value & 1.000 & 1.000 & 1.000 & 1.000 & 0.033 \\
\hline
\end{tabular}

\section{TABLE 2: Side Effects and Tramadol Consumption}

Values are presented as mean \pm standard deviation and number of patients.

No respiratory depression was observed in either group.

\section{Discussion}

The present study demonstrates that intravenous pentazocine administrated 10 min before surgery provides a reduction in intraoperative hemodynamic change, postoperative pain intensity, and tramadol consumption. Although laparoscopic cholecystectomy is associated with less tissue damage, port pain, abdominal organ nociception, and diaphragmatic irritation from residual pneumoperitoneum contribute to the total pain intensity perceived [35]. Therefore, some patients still suffer significant postoperative pain. Administrating an analgesic medication before the start of the surgical stimuli can decrease or block the development of central pain sensitization and then result in less postoperative pain [6].

MBP and HR are studied as an indirect reflection of intraoperative stress reaction. Patients in Group C had higher MBP and HR after pneumoperitoneum and during exploration of upper abdominal organs. This indicates that patients in Group $\mathrm{C}$ had a stronger stress reaction to surgical stimuli. The lower MBP and HR in Group P may contribute to the preemptive analgesic effect of pentazocine.

Pentazocine is a synthetically mixed agonist-antagonist narcotic (opioid analgesic) drug used to treat moderate to severe pain. The advantage of pentazocine is that it is a morphine antagonist and has not yet been found to produce tolerance or dependence [7]. Bao, et al. find that activating opioid receptors in the dorsal root ganglion causes intracellular $\mathrm{Ca}^{2+}$ release and $\mathrm{Ca}^{2+}$ entry, which leads to a release of excitatory neuropeptides [8]. It suggests that the preemptive effect of pentazocine may result from the blockade of opioid receptors. The specific mechanism is unclear.

No literature has been found about preemptive analgesia with pentazocine. Because the peak time of intravenous pentazocine is $2 \sim 3 \mathrm{~min}, 10 \mathrm{~min}$ prior to surgery was chosen as the time of preemptive analgesia in this clinical trial [9].

The incidences of these side effects were comparable between the two groups. No respiratory depression was observed in this study. The result is in line with the previous studies that pentazocine has relatively weak respiratory disturbances [1-2]. 
One limitation of our study is that laparoscopic cholecystectomy is a relatively small surgery, so the result of this study is limited and cannot be expanded to major surgeries. Future research will be conducted on major surgeries. There are many analgesic modes and ours is a simple one, so the analgesic method of this study may not be suitable for other groups.

\section{Conclusions}

Preoperative pentazocine can decrease hemodynamic changes, postoperative pain, and analgesic requirement in patients undergoing laparoscopic cholecystectomy.

\section{Additional Information \\ Disclosures}

Human subjects: Consent was obtained by all participants in this study. The Ethics Committee of the First Hospital of Jilin University issued approval 2016-291. Approval. Animal subjects: All authors have confirmed that this study did not involve animal subjects or tissue. Conflicts of interest: In compliance with the ICMJE uniform disclosure form, all authors declare the following: Payment/services info: All authors have declared that no financial support was received from any organization for the submitted work. Financial relationships: All authors have declared that they have no financial relationships at present or within the previous three years with any organizations that might have an interest in the submitted work. Other relationships: All authors have declared that there are no other relationships or activities that could appear to have influenced the submitted work.

\section{References}

1. Shook JE, Watkins WD, Camporesi EM: Differential roles of opioid receptors in respiration, respiratory disease, and opiate-induced respiratory depression. Am Rev Respir Dis. 1990, 142:895-909. 10.1164/ajrccm/142.4.895

2. Hoskin PI, Hanks GW: Opioid agonist-antagonist drugs in acute and chronic pain states . Drugs. 1991, 41:326-44. 10.2165/00003495-199141030-00002

3. Blichfeldt-Eckhardt MR, Ording H, Andersen C, Licht PB, Toft P: Early visceral pain predicts chronic pain after laparoscopic cholecystectomy. Pain. 2014, 155:2400-2407. 10.1016/j.pain.2014.09.019

4. Perry KT, Freedland SJ, Hu JC, Phelan MW, Kristo B, Gritsch AH, Rajfer J, Schulam PG: Quality of life, pain and return to normal activities following laparoscopic donor nephrectomy versus open mini-incision donor nephrectomy. J Urol. 2003, 169:2018-21. 10.1097/01.ju.0000067975.59772.b6

5. Mohtadi A, Nesioonpour S, Salari A, Akhondzadeh R, Masood Rad B, Aslani SM: The effect of single-dose administration of dexamethasone on postoperative pain in patients undergoing laparoscopic cholecystectomy. Anesth Pain Med. 2014, 4:e17872. 10.5812/aapm.17872

6. Rosero EB, Joshi GP: Preemptive, preventive, multimodal analgesia: what do they really mean?. Plast Reconstr Surg. 2014, 134:85S-93S. 10.1097/PRS.0000000000000671

7. King CD, Goodin B, Glover TL, Riley JL, Hou W, Staud R, Fillingim RB: Is the pain-reducing effect of opioid medication reliable? A psychophysical study of morphine and pentazocine analgesia. Pain. 2013, 154:476-83. 10.1016/j.pain.2012.12.009

8. Bao L, Jin SX, Zhang C, Wang LH, Xu ZZ, Zhang FX, Wang LC, Ning FS, Cai HJ, Guan JS, Xiao HS, Xu ZQ, He C, Hökfelt T, Zhou Z, Zhang X: Activation of delta opioid receptors induces receptor insertion and neuropeptide secretion. Neuron. 2003, 37:121-33. 10.1016/S08966273(02)01103-0

9. Prasad Verma PR, Chandak AR: Development of matrix controlled transdermal delivery systems of pentazocine: In vitro/in vivo performance. Acta Pharm. 2009, 59:171-86. 10.2478/v10007-009-0014-y 